\title{
Número de repetições para avaliação de caracteres em genótipos de feijão-caupi
}

\author{
Francisco Eduardo Torres ( $\left.{ }^{1}\right)$; Edvaldo Sagrilo $\left({ }^{2}\right)$; Paulo Eduardo Teodoro $\left({ }^{1 *}\right)$; \\ Larissa Pereira Ribeiro $\left({ }^{3}\right)$; Alberto Cargnelutti Filho $\left({ }^{4}\right)$
}

(1) Universidade Estadual de Mato Grosso do Sul (UEMS), Departamento de Fitotecnia, Programa de Pós-Graduação em Agronomia, Caixa Postal 25, 79200-000 Aquidauana (MS), Brasil.

(2) Embrapa Meio-Norte, Avenida Duque de Caxias, 5650, 64006220 Teresina (PI) Brasil.

(3) UEMS, Departamento de Nutrição de Plantas, Curso de Agronomia, 79200-000 Aquidauna (MS), Brasil.

(4) Universidade Federal de Santa Maria (UFSM), Departamento de Fitotecnia, Avenida Roraima, 1000, 97105-900 Santa Maria (RS), Brasil.

$\left({ }^{*}\right)$ Autor correspondente: eduteodoro@hotmail.com

Recebido: 8/nov./2014; Aceito: 5/fev./2015

\begin{abstract}
Resumo
O objetivo deste trabalho foi determinar o número de medições (repetições) necessário para avaliar caracteres de genótipos de feijão-caupi (Vigna unguiculata). Vinte genótipos de feijão-caupi de porte ereto e vinte de porte semiprostrado foram avaliados no Estado do Mato Grosso do Sul, em seis e quatro ensaios, respectivamente. Os dez ensaios foram conduzidos no delineamento blocos ao acaso, com quatro repetições. Foram mensurados os caracteres comprimento de vagem, massa de vagem, massa de grãos por vagem, número de grãos por vagem, massa de cem grãos e produtividade de grãos. Foram verificados os pressupostos do modelo matemático, realizada a análise de variância, estimado o coeficiente de repetibilidade e calculado o número de repetições. Ensaios com quatro repetições identificam genótipos superiores de feijão-caupi em relação aos caracteres comprimento de vagem, massa de vagem, massa de grãos por vagem, número de grãos por vagem, massa de cem grãos e produtividade de grãos, com, respectivamente, 84,57, 75,62, 73,14, 75,25, 81,53 e 79,19\% de exatidão no prognóstico de seu valor real.
\end{abstract}

Palavras-chave: Vigna unguiculata L., repetibilidade, planejamento experimental.

\section{Number of replicates for the evaluation of characters in cowpea genotypes}

\section{Abstract}

The objective of this study was to determine the number of measurements (replicates) necessary to predict the performance of cowpea (Vigna unguiculata) genotypes. Twenty genotypes of cowpea to growth habit erect and twenty semi-prostrate were carried out in Mato Grosso do Sul State, Brazil, in six and four trials, respectively. It was conducted ten trials in randomized complete blocks design with four replicates. The character length of pod, weight of pod, weight of grains per pod, number of seeds per pod, weight of hundred grains and grain yield were measured. Assumptions of the mathematical model were examined, analysis of variance was performed, the repeatability coefficient was estimated and the number of replicates was calculated. Trials with four replicates identify superior cowpea genotypes in relation to length of pod, weight of pod, weight of grains per pod, number of seeds per pod, weight of hundred grains and grain yield characters, with, respectively, 84.57, 75.62, 73.14, 75.25, 81.53 and $79.19 \%$ accuracy of the true prognostic value.

Key words: Vigna unguiculata L., repeatability, experimental planning.

\section{INTRODUÇÃO}

O feijão-caupi [Vigna unguiculata (L.) Walp.] é uma das fontes alimentares mais importantes e estratégicas para as regióes tropicais e subtropicais do planeta. $\mathrm{O}$ Brasil é o terceiro maior produtor mundial dessa cultura, que é cultivada sobretudo nas regiôes Norte e Nordeste, constituindo-se no prato básico das classes de menor poder aquisitivo (Oliveira et al., 2013). Contudo, apesar da grande produção brasileira, segundo Almeida et al. (2014) há déficit permanente de oferta nessas regiōes, uma vez que a produtividade média brasileira é extremamente 
baixa (300 $\left.\mathrm{kg} \mathrm{ha}^{-1}\right)$. Santos et al. (2014a) enfatizam que o melhoramento genético dessa cultura é o principal modo de aumentar a produtividade, por meio da seleção de genótipos altamente produtivos e adaptados às condiçóes edafoclimáicas brasileiras.

Em ensaios de genótipos de feijão-caupi, caracteres como o comprimento de vagem, massa de vagem, massa de grãos por vagem, número de grãos por vagem, massa de cem grãos e produtividade de grãos são comumente avaliados. Nesses ensaios, para a correta discriminação dos genótipos, é importante que esses caracteres sejam avaliados com melhor precisão (menor dispersão) e com exatidão ou acurácia (sem viés entre a estimativa e o parâmetro, ou seja, sem tendência), ou seja, de acordo com os conceitos de precisão e exatidão ou acurácia discutidos em Monico et al. (2009). Para alcançar a precisão desejada, é importante dimensionar adequadamente o tamanho e a forma de parcela, o tamanho de amostra e o número de repetiçóes com base no caráter de interesse.

Com base em caracteres de genótipos de feijáo-caupi, estudos sobre relaçôes lineares entre caracteres (Silva \& Neves, 2011; Correa et al., 2012; Oliveira et al., 2013; Almeida et al., 2014; Santos et al., 2014a), desempenho agronômico e divergência genética (Santos et al., 2014b, c), estimativas de parâmetros genéticos (Matos et al., 2009; Andrade et al., 2010; Correa et al., 2012) e adaptabilidade e estabilidade (Barros et al., 2013) têm sido realizados. Nessas pesquisas tem-se utilizado o delineamento blocos ao acaso, com três e quatro repetiçóes.

A investigação da necessidade de redimensionar o número de repetições é possível de ser realizada a partir de dados de ensaios de genótipos com base em estimativas de coeficiente de repetibilidade obtidas por meio da análise de variância (Cruz, 2006). Nesse cenário, o fato de serem necessários experimentos específicos para dimensionar o número de repetiçóes, além de maximizar o aproveitamento de dados existentes, possibilitaria a economia de tempo, recursos humanos e financeiros.

A partir do coeficiente de repetibilidade, o dimensionamento do número de repetiçôes foi realizado em ensaios de competição de genótipos de feijão (Cargnelutti et al., 2009), de soja (Storck et al., 2009), de milho (Cargnelutti et al., 2010) e de arroz irrigado (Cargnelutti et al., 2012). Nesses estudos, os autores constataram que, para avaliar a produtividade de grãos dessas culturas, ensaios com quatro repetições possibilitam a identificação de genótipos superiores de feijão, de soja, de milho e de arroz irrigado com 85, 80, 81 e $79 \%$ de precisão, respectivamente.

Além da produtividade de grãos, o dimensionamento do número de repetiçóes para avaliar outros caracteres de feijāo (Cargnelutti \& Ribeiro, 2010), de soja (Cargnelutti \& Gonçalves, 2011) e de milho (Cargnelutti \& Guadagnin, 2011) tem sido realizado a partir do coeficiente de repetibilidade. De maneira geral, nesses estudos foi evidenciado que, para a mesma precisão, há variabilidade do número de repetiçóes entre caracteres. No entanto, referências ao emprego da análise de repetibilidade para a estimativa do número de repetiçóes de caracteres de feijão-caupi não foram encontradas na literatura. Assim, o objetivo deste trabalho foi determinar o número de mediçóes (repetiçôes) necessário para avaliar os caracteres comprimento de vagem, massa de vagem, massa de grãos por vagem, número de grãos por vagem, massa de cem grãos e produtividade de grãos de genótipos de feijão-caupi.

\section{MATERIAL E MÉTODOS}

Genótipos de feijão-caupi [Vigna unguiculata (L.) Walp.], de hábitos de crescimento ereto (15 linhagens: MNC99-537F-1, MNC99-537F-4, MNC99-541-F5, MNC99-541-F8, IT93K-93-10, MNC99-519D-1-1-5, MNC00-544D-10-1-2-2, MNC00-544D-14-1-2-2, MNC00-553D-8-1-2-2, MNC00-553D-8-1-2-3, MNC00561G-6, EV X 63-10E, MNC99542F-5, EV X 91-2E-2 e MNC99-557F-2 e cinco cultivares: Pretinho, Fradinho-2, BRS Guariba, Patativa e Vita-7) e semiprostrado (18 linhagens: MNC99-505G-11, MNC99-507G-4, MNC99-507G-8, BRS Xiquexique, MNC99-510G-8, MNC99-510F-16, TE97309G-18, TE97-304G-4, TE97-304G-12, TE97-309G-24, MNC99-508G-1, MNC99-541F-15, MNC99-541F-18, MNC99-541F-21, MNC99-542F-5, MNC99-542F-7, MNC99-547F-2 e CNC x 409-11F-P2 e duas cultivares: BRS Paraguaçu e BR 17-Gurgueia), oriundos do programa de melhoramento genético de feijão-caupi da Embrapa Meio-Norte, foram avaliados em dez ensaios de valor de cultivo e uso conduzidos no Estado do Mato Grosso do Sul (Tabela 1).

Os dez ensaios foram realizados no delineamento blocos ao acaso com quatro repetiçóes (blocos). As unidades experimentais foram compostas de quatro fileiras de $5 \mathrm{~m}$ de comprimento com espaçamento de $0,5 \mathrm{~m}$ entre fileiras e $0,25 \mathrm{~m}$ entre plantas na fileira. As avaliaçóes foram realizadas nas duas fileiras centrais (área útil $=5 \mathrm{~m}^{2}$ ). Em cada unidade experimental, de cada experimento, foram mensurados os caracteres: comprimento de vagem, $(\mathrm{CV}, \mathrm{em} \mathrm{cm})$; massa de vagem (MV, em g); massa de grãos por vagem (MGV, em g); número de grãos por vagem (NGV); massa de cem grãos (MCG, em g) e produtividade de grãos a $13 \%$ de umidade (PROD, em $\mathrm{t} \mathrm{ha}^{-1}$ ). Em cada unidade experimental, os caracteres $\mathrm{CV}, \mathrm{MV}$, MGV e NGV foram obtidos pela média de mediçóes feitas em cinco vagens, tomadas aleatoriamente nas duas fileiras centrais. A MCG foi obtida por MGV/ $\mathrm{NGV} \times 100$. A PROD foi obtida a partir de todas as plantas das duas fileiras centrais (área útil $=5 \mathrm{~m}^{2}$ ), corrigida para $13 \%$ de umidade, valor comumente utilizado para avaliar a PROD em feijão-caupi (Almeida et al., 2014; Santos et al., 2014a, b), sendo extrapolada para t $\mathrm{ha}^{-1}$. 
Tabela 1. Número do ensaio (NE), número de genótipos (NG), hábito de crescimento, ano agrícola, local, latitude, longitude, altitude, classificação climática de Köppen-Geiger e data de semeadura de genótipos de feijão-caupi [Vigna unguiculata (L.) Walp.], avaliados no Estado do Mato Grosso do Sul

\begin{tabular}{|c|c|c|c|c|c|c|c|c|c|}
\hline NE & NG & Hábito & Ano & Local & Latitude & Longitude & Altitude & $\begin{array}{c}\text { Classificação } \\
\text { de Köppen- } \\
\text { Geiger }\end{array}$ & Semeadura \\
\hline 1 & 20 & Ereto & 2005 & Aquidauana & $22^{\circ} 01^{\prime} \mathrm{S}$ & $54^{\circ} 05^{\prime} \mathrm{W}$ & $430 \mathrm{~m}$ & Aw & $21 / 3 / 2005$ \\
\hline 2 & 20 & Ereto & 2005 & $\begin{array}{c}\text { Chapadão } \\
\text { do Sul }\end{array}$ & $18^{\circ} 05^{\prime} \mathrm{S}$ & $52^{\circ} 04^{\prime} \mathrm{W}$ & 790 m & Aw & $14 / 3 / 2005$ \\
\hline 3 & 20 & Ereto & 2005 & Dourados & $20^{\circ} 03^{\prime} \mathrm{S}$ & $55^{\circ} 05^{\prime} \mathrm{W}$ & 147 m & Cwa & $7 / 4 / 2005$ \\
\hline 4 & 20 & Ereto & 2006 & Aquidauana & $22^{\circ} 01^{\prime} \mathrm{S}$ & $54^{\circ} 05^{\prime} \mathrm{W}$ & $430 \mathrm{~m}$ & Aw & $2 / 3 / 2006$ \\
\hline 5 & 20 & Ereto & 2006 & Dourados & $20^{\circ} 03^{\prime} \mathrm{S}$ & $55^{\circ} 05^{\prime} \mathrm{W}$ & 147 m & Cwa & $27 / 2 / 2006$ \\
\hline 6 & 20 & Ereto & 2006 & Primavera & $15^{\circ} 33^{\prime} \mathrm{S}$ & $54^{\circ} 17^{\prime} \mathrm{W}$ & $636 \mathrm{~m}$ & Aw & $15 / 3 / 2006$ \\
\hline 7 & 20 & Semiprostrado & 2005 & Aquidauana & $22^{\circ} 01^{\prime} \mathrm{S}$ & $54^{\circ} 05^{\prime} \mathrm{W}$ & $430 \mathrm{~m}$ & Aw & $5 / 6 / 2005$ \\
\hline 8 & 20 & Semiprostrado & 2005 & $\begin{array}{c}\text { Chapadão } \\
\text { do Sul }\end{array}$ & $18^{\circ} 05^{\prime} \mathrm{S}$ & $52^{\circ} 04^{\prime} \mathrm{W}$ & $790 \mathrm{~m}$ & Aw & $10 / 6 / 2005$ \\
\hline 9 & 20 & Semiprostrado & 2006 & Aquidauana & $22^{\circ} 01^{\prime} \mathrm{S}$ & $54^{\circ} 05^{\prime} \mathrm{W}$ & $430 \mathrm{~m}$ & Aw & $28 / 5 / 2006$ \\
\hline 10 & 20 & Semiprostrado & 2006 & Dourados & $20^{\circ} 03^{\prime} \mathrm{S}$ & $55^{\circ} 05^{\prime} \mathrm{W}$ & 147 m & Cwa & $30 / 6 / 2006$ \\
\hline
\end{tabular}

Em cada um dos dez ensaios, os dados dos caracteres CV, MV, MGV, NGV, MCG e PROD seguiram um modelo estatístico de delineamento blocos ao acaso dado por: $Y_{i j}=\mu+\tau_{i}+\beta_{j}+\varepsilon_{i j}$, no qual $Y_{i j}$ é o valor observado da variável resposta na parcela, $i j$, $\mu$ é a média geral, $\tau_{i}$ é o efeito do genótipo $(i=1,2, \ldots, 20), \beta_{j}$ é o efeito do bloco $(j=1$, $2,3,4)$ e $\varepsilon_{i j}$ é o efeito do erro experimental suposto normal e independentemente distribuído com média 0 e variância comum $\sigma^{2}$ (Storck et al., 2011). Os testes de KolmogorovSmirnov, Bartlett e aditividade de Tukey foram realizados para verificar o atendimento, respectivamente, das pressuposiçóes de normalidade dos erros, homogeneidade de variâncias e aditividade do modelo matemático. Com base nos resultados da análise de variância, foram obtidas as estimativas do quadrado médio de bloco $\left(\mathrm{QM}_{\mathrm{B}}\right)$, do quadrado médio de genótipo $\left(\mathrm{QM}_{\mathrm{G}}\right)$, do quadrado médio do erro $\left(\mathrm{QM}_{\mathrm{E}}\right)$ e do valor do teste $\mathrm{F}$ para genótipo $\left(\mathrm{Fc}=\mathrm{QM}_{\mathrm{G}} / \mathrm{QM}_{\mathrm{E}}\right)$. Após, foi estimada a acurácia seletiva (AS) (Resende \& Duarte, 2007) por meio da expressão $\mathrm{AS}=(1-(1 / \mathrm{Fc}))^{0,5}$. Posteriormente, com base em AS, foi avaliada a precisão experimental de acordo com os limites de classes estabelecidos em Resende $\&$ Duarte (2007).

Foram consideradas as avaliaçôes em cada bloco como mediçôes realizadas no mesmo indivíduo (genótipo) e foi estimado o coeficiente de repetibilidade (r), em cada caráter e ensaio, por meio da análise de variância. Nesse estudo, o coeficiente de repetibilidade é o coeficiente de correlação intraclasse para genótipos e é estimado por meio da expressão $r=\left[\left(Q M_{G}-Q M_{E}\right) / J\right] /\left[\left(Q M_{G}-Q M_{E}\right) / J+Q M_{E}\right]$, em que J é o número de medições ou repetições (Cruz \& Regazzi, 1997; Cruz, 2006).

O número de mediçôes ou repetiçóes $(\mathrm{J})$ necessário para predizer o valor real dos indivíduos (genótipos), com base nos coeficientes de determinação genotípico $\left(\mathrm{R}^{2}\right)$ preestabelecidos $(0,70,0,75,0,80,0,85,0,90$ e 0,95$)$, foi calculado por meio da expressão $J=\left[R^{2}(1-r)\right] /\left[\left(1-R^{2}\right) r\right]$ (Cruz \& Regazzi,
1997). O coeficiente de determinação genotípico $\left(R^{2}\right)$, que representa a certeza da predição do valor real dos genótipos selecionados, com base em J medições realizadas, foi obtido pela expressão $R^{2}=[J r] /[1+r(J-1)]$, em que J é o número de mediçôes realizadas $(\mathrm{J}=4$ blocos neste estudo) e r é o coeficiente de repetibilidade (Cruz, 2006). Ainda, com base na média do coeficiente de repetibilidade (r) entre os dez ensaios, em cada um dos caracteres, foi calculado o coeficiente de determinação genotípico $\left(\mathrm{R}^{2}\right)$ em função do número de repetiçôes (J variando de 0 até 50). Apesar de ensaios com zero repetição náo ter sentido prático e com 50 repetiçôes serem praticamente inviáveis de realizaçáo, optou-se por esses limites para demonstrar o comportamento da relaçáo entre $\mathrm{R}^{2}$ e J, com base em um valor fixo de $\mathrm{r}(\mathrm{r}=$ média dos dez ensaios). As análises estatísticas foram realizadas com o auxílio do programa GENES (Cruz, 2013) e do aplicativo Microsoft Office Excel.

\section{RESULTADOS E DISCUSSÃO}

Nos 60 casos analisados (seis caracteres $\times$ dez ensaios), pelo teste de Kolmogorov-Smirnov, verificou-se que os erros ajustaram-se à distribuição normal ( $p>0,05)$. Em 50 casos (90\%), pelo teste de Bartlett, constatou-se que as variâncias residuais foram homogêneas $(p>0,05)$. Em apenas 57 casos (95\%), o teste de aditividade de Tukey revelou aditividade do modelo matemático $(\mathrm{p}>0,05)$. Portanto, os elevados percentuais de atendimento das pressuposiçóes de normalidade dos erros, homogeneidade de variâncias e aditividade do modelo matemático do delineamento em blocos ao acaso conferem adequabilidade para a aplicaçáo dos testes de hipóteses (teste F), para as fontes de variação (bloco e genótipo) da análise de variância (Storck et al., 2011). Entre os 60 casos (seis caracteres $\times$ dez ensaios), o teste $\mathrm{F}$ da análise de variância revelou efeito de bloco significativo 
$(p \leq 0,05)$ em 35 casos $(58,33 \%)$, o que evidencia que os blocos foram heterogêneos e que o uso do delineamento blocos ao acaso foi eficiente. Por outro lado, em 25 casos (41,67\%), os blocos não foram heterogêneos e, nesses casos, o delineamento inteiramente casualizado poderia ter sido utilizado. Portanto, apesar de ser constatado que em $41,67 \%$ dos casos não houve significância do efeito de blocos, o uso de blocos deve continuar sendo utilizado nessas áreas experimentais como forma de garantir o controle dessa fonte de heterogeneidade, no caso de sua existência.

As médias dos caracteres comprimento de vagem, massa de vagem, massa de grãos por vagem, número de grãos por vagem, massa de cem grãos e produtividade de grãos (Tabela 2) foram similares às médias obtidas em outros ensaios de genótipos de feijáo-caupi (Matos et al., 2009; Andrade et al., 2010; Silva \& Neves, 2011; Correa et al., 2012; Barros et al., 2013; Oliveira et al., 2013; Almeida et al., 2014; Santos et al., 2014a, b), o que revela adequabilidade desse banco de dados para o estudo proposto, pelo fato destes representarem situaçôes reais de ensaios de campo.

Em relaçáo ao comprimento de vagem, à massa de cem grãos e à produtividade de grãos, houve efeito de genótipo significativo $(\mathrm{p} \leq 0,05)$ nos dez ensaios, o que evidencia que é possível identificar os genótipos superiores devido à variabilidade genética existente. Já quanto à massa de vagem, à massa de grãos por vagem e ao número de grãos por vagem, não houve efeito significativo de genótipo apenas no ensaio 8. Portanto, para os três caracteres desse ensaio, a não discriminação dos genótipos, por meio do teste $\mathrm{F}$, pode não ser devido à não existência de variabilidade genética e sim, provavelmente, à menor precisão experimental (Resende \& Duarte, 2007). Nos 57 casos (95\%) com efeito significativo de genótipo, a média da acurácia seletiva (AS) e dos coeficientes de repetibilidade (r) e de determinação genotípico $\left(\mathrm{R}^{2}\right)$, com base nas quatro repetiçóes, foi de $0,880,0,494$ e 0,778 , respectivamente. Enquanto, entre os três caracteres do ensaio 8 , em que não foram detectadas diferenças significativas, as médias de AS, $r$ e $\mathrm{R}^{2}$ foram, respectivamente, $0,649,0,154$ e 0,421 , o que reforça a hipótese de que a não identificação de diferenças entre os genótipos está associada à menor precisão experimental.

Escores de acurácia seletiva (AS) superiores a 0,90, o que equivale ao coeficiente de determinação genotípico $\left(\mathrm{R}^{2}\right)$ de $81 \%$, são almejados em experimentos, pois conferem precisão experimental muito alta na discriminação dos genótipos em avaliação (Resende \& Duarte, 2007). Nesses dez ensaios de feijão-caupi, a AS oscilou entre 0,632 (massa de grãos por vagem no ensaio 8) e 0,962 (produtividade de grãos nos ensaios 3 e 10), com média de 0,868 . De acordo com limites de classes estabelecidos em Resende $\&$ Duarte (2007), dos 60 casos, 26 apresentaram precisão experimental muito alta (AS $\geq 0,90), 31$ com precisão alta $(0,70 \leq \mathrm{AS}<0,90)$ e três casos com precisão moderada $(0,50 \leq \mathrm{AS}<0,70)$ (Tabela 2). Portanto, pode-se inferir que houve variabilidade das precisóes experimentais entre os caracteres e os ensaios e, de maneira geral, esses caracteres foram avaliados em condiçôes experimentais satisfatórias. Variabilidade de precisóes experimentais, com base em AS, entre caracteres e ensaios com genótipos de feijão (Cargnelutti \& Ribeiro, 2010), de soja (Cargnelutti \& Gonçalves, 2011) e de milho (Cargnelutti \& Guadagnin, 2011) e arroz irrigado (Cargnelutti et al., 2012), foi verificada nesses estudos.

O coeficiente de repetibilidade variou entre 0,143 (massa de grãos por vagem no ensaio 8) e 0,759 (produtividade de grãos no ensaio 10), com média de 0,477 (Tabela 3). A variabilidade de $\mathrm{r}$, entre os caracteres e ensaios, é particularmente importante neste estudo por representar distintas situaçóes reais e, assim, possibilitar inferências em relação ao número de repetiçóes (J), com aplicaçôes gerais. Variabilidade de r e, consequentemente, na estimativa do número de repetiçóes (J) entre caracteres e entre ensaios também foi verificada nas culturas de feijão (Cargnelutti et al., 2009; Cargnelutti \& Ribeiro, 2010), de soja (Storck et al., 2009; Cargnelutti \& Gonçalves, 2011), de milho (Cargnelutti et al., 2010; Cargnelutti \& Guadagnin, 2011) e de arroz irrigado (Cargnelutti et al., 2012).

$\mathrm{O}$ coeficiente determinação genotípico $\left(\mathrm{R}^{2}\right)$, obtido a partir de quatro repetiçóes, oscilou entre 39,93\% (massa de grãos por vagem no ensaio 8 ) e 92,64\% (produtividade de grãos no ensaio 10) (Tabela 3). Assim, com base nesses casos extremos, pode-se inferir que quatro repetições possibilitaram detectar diferenças genotípicas com 39,93\% e 92,64\% de certeza na predição do valor real do genótipo, em relação à massa de grãos por vagem no ensaio $8 \mathrm{e}$ à produtividade de grãos no ensaio 10 , respectivamente (Tabela 3 ). Para os demais caracteres e ensaios, a precisão foi entre 39,93\% e $92,64 \%$. Redimensionar o número de repetiçóes para avaliar esses caracteres para precisão experimental muito alta, ou seja, $A S=0,90$ ou $R^{2}=81 \%$, a partir do menor valor de $r$ $(\mathrm{r}=0,143$ para a massa de grãos por vagem no ensaio 8$)$, por meio da expressão $J=\left[R^{2}(1-r)\right] /\left[\left(1-R^{2}\right) r\right]$, resultaria em $J=[0,81 \times(1-0,143)] /[(1-0,81) \times 0,143]=26$ repetiçóes. Esse número de repetiçóes garantiria acurácia seletiva maior ou igual a 0,90 para todos os caracteres e ensaios. No entanto, realizar experimentos de campo com 26 repetições é difícil e/ou impraticável.

Para cada caráter, a média de $\mathrm{r}$ dos dez ensaios pode representar adequadamente os ensaios de feijão-caupi e, portanto, o redimensionamento do número de repetiçóes a partir de $r$ médio parece ser o procedimento adequado. Por esse raciocínio, para conseguir coeficiente de determinação genotípico $\left(R^{2}\right)$ de $81 \%$ a partir das médias de $r$ do comprimento de vagem $(0,578)$, da massa de vagem $(0,437)$, da massa de grãos por vagem $(0,405)$, do número de grãos por vagem $(0,432)$, da massa de cem grãos $(0,525)$ e da produtividade de grãos $(0,488)$ (Tabela 3), seriam necessárias, 3,1, 5,5, 6,3, 5,6, 3,9 e 4,5 repetiçóes, respectivamente. No entanto, na prática, experimentos devem ser realizados com número 
Tabela 2. Resumo da análise de variância [número de graus de liberdade (GL) e quadrado médio para as fontes de variação bloco, genótipo e erro], média, acurácia seletiva (AS), valor-p do teste de Kolmogorov-Smirnov para a normalidade dos erros, valor-p do teste de Bartlett para a homogeneidade de variâncias residuais e valor-p do teste de aditividade de Tukey, para seis caracteres de genótipos de feijão-caupi, avaliados em dez ensaios ${ }^{(1)}$

\begin{tabular}{|c|c|c|c|c|c|c|c|c|c|c|c|}
\hline $\begin{array}{l}\text { Fonte de } \\
\text { variação }\end{array}$ & GL & Ensaio 1 & Ensaio 2 & Ensaio 3 & Ensaio 4 & Ensaio 5 & Ensaio 6 & Ensaio 7 & Ensaio 8 & Ensaio 9 & $\begin{array}{c}\text { Ensaio } \\
10\end{array}$ \\
\hline \multicolumn{12}{|c|}{ Comprimento de vagem, em $\mathrm{cm}$} \\
\hline Bloco & 3 & $5,4588^{*}$ & $1,7743^{\text {ns }}$ & $0,8005^{\text {ns }}$ & $3,5320^{\text {ns }}$ & $8,4715^{*}$ & $1,7220^{\text {ns }}$ & $0,8645^{\text {ns }}$ & $5,6135^{*}$ & $6,1783^{*}$ & $0,2246^{\mathrm{ns}}$ \\
\hline Genótipo & 19 & $11,9660^{*}$ & $14,3254^{*}$ & $10,7962^{*}$ & $14,0790^{*}$ & $11,0868^{*}$ & $3,4441^{*}$ & $5,7383^{*}$ & $8,1174^{*}$ & $6,7818^{*}$ & $6,4601^{*}$ \\
\hline Erro & 57 & 1,1195 & 1,2107 & 1,1702 & 1,4362 & 1,1333 & 1,1211 & 1,3160 & 1,3442 & 1,5772 & 1,3406 \\
\hline Média & - & 17,18 & 17,29 & 16,27 & 17,50 & 16,56 & 17,78 & 18,47 & 19,34 & 18,46 & 18,22 \\
\hline $\mathrm{AS}^{(2)}$ & - & 0,952 & 0,957 & 0,944 & 0,948 & 0,948 & 0,821 & 0,878 & 0,913 & 0,876 & 0,890 \\
\hline Normalidade & - & 0,988 & 0,973 & 0,977 & 0,417 & 0,908 & 0,301 & 0,877 & 0,949 & 0,610 & 0,537 \\
\hline Homogeneidade & - & 0,322 & 0,887 & 0,572 & 0,936 & 0,713 & 0,133 & 0,830 & 0,726 & 0,595 & 0,111 \\
\hline Aditividade & - & 0,099 & 0,806 & 0,413 & 0,278 & 0,337 & 0,205 & 0,146 & 0,047 & 0,780 & 0,271 \\
\hline \multicolumn{12}{|c|}{ Massa de vagem, em g } \\
\hline Bloco & 3 & $0,4970^{*}$ & $0,2476^{\text {ns }}$ & $0,1086^{\text {ns }}$ & $0,6386^{*}$ & $1,5559^{*}$ & $0,7104^{*}$ & $0,0923^{\text {ns }}$ & $1,4043^{*}$ & $0,9360^{*}$ & $0,5904^{*}$ \\
\hline Genótipo & 19 & $0,7576^{*}$ & $0,7910^{*}$ & $0,7173^{*}$ & $1,1911^{*}$ & $0,6378^{*}$ & $0,3273^{*}$ & $0,6695^{*}$ & $0,4615^{\text {ns }}$ & $0,7767^{*}$ & $0,2744^{*}$ \\
\hline Erro & 57 & 0,1088 & 0,1694 & 0,1140 & 0,1798 & 0,1050 & 0,1470 & 0,1565 & 0,2614 & 0,1560 & 0,1237 \\
\hline Média & - & 2,79 & 2,47 & 2,10 & 2,86 & 1,83 & 2,66 & 3,05 & 2,84 & 3,51 & 2,32 \\
\hline $\mathrm{AS}^{(2)}$ & - & 0,925 & 0,887 & 0,917 & 0,921 & 0,914 & 0,742 & 0,875 & 0,658 & 0,894 & 0,741 \\
\hline Normalidade & - & 0,954 & 0,925 & 0,465 & 0,687 & 0,868 & 0,838 & 0,537 & 0,976 & 0,889 & 0,885 \\
\hline Homogeneidade & - & 0,771 & 0,519 & 0,825 & 0,203 & 0,623 & 0,034 & 0,159 & 0,702 & 0,586 & 0,273 \\
\hline Aditividade & - & 0,823 & 0,492 & 0,168 & 0,564 & 0,262 & 0,202 & 0,764 & 0,116 & 0,228 & 0,887 \\
\hline \multicolumn{12}{|c|}{ Massa de grãos por vagem, em g } \\
\hline Bloco & 3 & $0,3061^{*}$ & $0,1777^{\text {ns }}$ & $0,1057^{\text {ns }}$ & $0,4054^{*}$ & $1,1048^{*}$ & $0,7082^{*}$ & $0,1354^{\text {ns }}$ & $0,8490^{*}$ & $0,4111^{*}$ & $0,5789 *$ \\
\hline Genótipo & 19 & $0,4799^{*}$ & $0,4049^{*}$ & $0,4397^{*}$ & $0,7154^{*}$ & $0,4336^{*}$ & $0,2161^{*}$ & $0,4436^{*}$ & $0,3068^{\text {ns }}$ & $0,4408^{*}$ & $0,1917^{*}$ \\
\hline Erro & 57 & 0,0795 & 0,1232 & 0,0855 & 0,1 & 0,0757 & 0,09 & 0,1142 & 43 & 992 & 0,0887 \\
\hline Média & - & 2,19 & 1,82 & 1,53 & 2,07 & 1,24 & 1,95 & 2,34 & 1,95 & 2,57 & 1,50 \\
\hline $\mathrm{AS}(2)$ & - & 0,913 & 0,834 & 0,898 & 0,924 & 0,909 & 0,743 & 0,862 & 0,632 & 0,880 & 0,733 \\
\hline Normalidade & - & 0,934 & 0,973 & 0,921 & 0,754 & 0,739 & 0,986 & 0,707 & 0,977 & 0,963 & 0,982 \\
\hline Homogeneidade & - & 0,932 & 0,083 & 0,700 & 0,338 & 0,650 & 0,354 & 0,016 & 0,714 & 0,971 & 0,470 \\
\hline Aditividade & - & 0,771 & 0,576 & 0,321 & 0,567 & 0,263 & 0,215 & 0,619 & 0,185 & 0,631 & 0,585 \\
\hline \multicolumn{12}{|c|}{ Número de grãos por vagem } \\
\hline Bloco & 3 & $11,5298^{*}$ & $3,0273^{\text {ns }}$ & $1,2493^{\mathrm{ns}}$ & $9,9013^{*}$ & $8,3098^{*}$ & $4,5405^{\text {ns }}$ & $0,2992^{\text {ns }}$ & $6,5340^{\text {ns }}$ & $2,5165^{\mathrm{ns}}$ & $0,3592^{\text {ns }}$ \\
\hline Genótipo & 19 & $10,2936^{*}$ & $11,5146^{*}$ & $12,2088^{*}$ & $9,7126^{*}$ & $9,2426^{*}$ & $6,5283^{*}$ & $6,8331^{*}$ & $5,8357^{\text {ns }}$ & $7,9911^{*}$ & $5,5010^{*}$ \\
\hline Erro & 57 & 1,7042 & 2,4951 & 1,4269 & 2,0547 & 1,5505 & 1,8693 & 2,4150 & 3,3277 & 2,1243 & 1,8412 \\
\hline Média & - & 10,19 & 9,65 & 9,43 & 11,50 & 9,28 & 11,26 & 12,05 & 12,15 & 12,81 & 11,22 \\
\hline $\operatorname{AS}(2)$ & - & 0,913 & 0,885 & 0,940 & 0,888 & 0,912 & 0,845 & 0,804 & 0,656 & 0,857 & 0,816 \\
\hline Normalidade & - & 0,534 & 0,780 & 0,823 & 0,836 & 0,811 & 0,630 & 0,602 & 0,988 & 0,811 & 0,948 \\
\hline Homogeneidade & - & 0,954 & 0,385 & 0,404 & 0,157 & 0,182 & 0,042 & 0,856 & 0,339 & 0,324 & 0,979 \\
\hline Aditividade & - & 0,805 & 0,631 & 0,602 & 0,704 & 0,232 & 0,605 & 0,056 & 0,445 & 0,568 & 0,698 \\
\hline \multicolumn{12}{|c|}{ Massa de cem grãos, em g } \\
\hline Bloco & 3 & $6,7190^{\text {ns }}$ & $4,1707^{\text {ns }}$ & $17,6294^{*}$ & $1,7945^{\text {ns }}$ & $65,7631^{*}$ & $27,6563^{*}$ & $12,3473^{*}$ & $24,8103^{*}$ & $7,3382^{\text {ns }}$ & $43,6789^{*}$ \\
\hline Genótipo & 19 & $19,3135^{*}$ & $21,4138^{*}$ & $18,5472^{*}$ & $29,7848^{*}$ & $26,9912^{*}$ & $21,8567^{*}$ & $26,8346^{*}$ & $12,1545^{*}$ & $11,9478^{*}$ & $10,9989^{*}$ \\
\hline Erro & 57 & 4,5302 & 2,1780 & 3,2175 & 2,4788 & 4,6445 & 3,2877 & 3,4020 & 3,9925 & 3,1473 & 3,8499 \\
\hline Média & - & 21,66 & 18,95 & 16,19 & 17,98 & 13,13 & 17,47 & 19,51 & 15,90 & 20,07 & 13,33 \\
\hline $\mathrm{AS}(2)$ & - & 0,875 & 0,948 & 0,909 & 0,957 & 0,910 & 0,922 & 0,934 & 0,819 & 0,858 & 0,806 \\
\hline Normalidade & - & 0,870 & 0,417 & 0,871 & 0,960 & 0,986 & 0,988 & 0,661 & 0,645 & 0,749 & 0,393 \\
\hline Homogeneidade & - & 0,023 & 0,926 & 0,587 & 0,148 & 0,137 & 0,188 & 0,025 & 0,775 & 0,085 & 0,069 \\
\hline Aditividade & - & 0,267 & 0,646 & 0,335 & 0,906 & 0,204 & 0,328 & 0,254 & 0,042 & 0,799 & 0,634 \\
\hline \multicolumn{12}{|c|}{ Produtividade de grãos, em $\mathrm{t} \mathrm{ha}^{-1}$} \\
\hline Bloco & 3 & $0,5850^{*}$ & $0,1608^{*}$ & $0,1711^{*}$ & $0,0073^{\text {ns }}$ & $0,1332^{*}$ & $0,4014^{*}$ & $0,0231^{\mathrm{ns}}$ & $0,1288^{*}$ & $0,0506^{*}$ & $0,4768^{*}$ \\
\hline Genótipo & 19 & $0,1812^{*}$ & $0,1415^{*}$ & $0,6037^{*}$ & $0,0448^{*}$ & $0,0395^{*}$ & $0,0702^{*}$ & $0,0743^{*}$ & $0,1098^{*}$ & $0,0420^{*}$ & $0,1922 *$ \\
\hline Erro & 57 & 0,0665 & 0,0495 & 0,0456 & 0,0056 & 0,0051 & 0,0180 & 0,0364 & 0,0296 & 0,0098 & 0,0141 \\
\hline Média & - & 1,155 & 0,911 & 0,925 & 0,219 & 0,211 & 0,555 & 1,154 & 0,394 & 0,343 & 0,477 \\
\hline $\mathrm{AS}(2)$ & - & 0,795 & 0,806 & 0,962 & 0,936 & 0,933 & 0,862 & 0,714 & 0,855 & 0,875 & 0,962 \\
\hline Normalidade & - & 0,996 & 0,978 & 0,995 & 0,439 & 0,591 & 0,703 & 0,712 & 0,983 & 0,939 & 0,988 \\
\hline Homogeneidade & - & 0,349 & 0,845 & 0,344 & 0,149 & 0,035 & 0,968 & 0,960 & 0,152 & 0,416 & 0,768 \\
\hline Aditividade & - & 0,768 & 0,344 & 0,317 & 0,878 & 0,902 & 0,387 & 0,246 & 0,116 & 0,391 & 0,003 \\
\hline
\end{tabular}

* Efeito significativo pelo teste $\mathrm{F}$ a $5 \%$ de probabilidade. ${ }^{\text {ns }}$ não significativo. ${ }^{(1)}$ Ensaios descritos na Tabela $1 .{ }^{(2)}$ Limites de classes de precisão experimental estabelecidos por Resende \& Duarte (2007): muito alta (AS $\geq 0,90)$, alta $(0,70 \leq \mathrm{AS}<0,90)$, moderada $(0,50 \leq \mathrm{AS}<0,70)$ e baixa $(\mathrm{AS}<0,50)$. 
Tabela 3. Estimativa dos coeficientes de repetibilidade (r), dos coeficientes de determinação genotípico $\left(\mathrm{R}^{2}\right)$ e do número de medições (repetiçóes) $(\mathrm{J})^{(1)}$ associado a distintos $\mathrm{R}^{2}$, de seis caracteres de genótipos de feijão-caupi, avaliados em dez ensaios ${ }^{(2)}$

\begin{tabular}{|c|c|c|c|c|c|c|c|c|c|c|c|}
\hline Estatística & Ensaio 1 & Ensaio 2 & Ensaio 3 & Ensaio 4 & Ensaio 5 & Ensaio 6 & Ensaio 7 & Ensaio 8 & Ensaio 9 & Ensaio 10 & Média $^{(3)}$ \\
\hline \multicolumn{12}{|c|}{ Comprimento de vagem, em cm } \\
\hline $\mathrm{R}$ & 0,708 & 0,730 & 0,673 & 0,688 & 0,687 & 0,341 & 0,457 & 0,557 & 0,452 & 0,488 & 0,578 \\
\hline $\mathrm{R}^{2}(\%)$ & 90,64 & 91,55 & 89,16 & 89,80 & 89,78 & 67,45 & 77,07 & 83,44 & 76,74 & 79,25 & 84,57 \\
\hline$J\left(R^{2}=0,70\right)$ & 1,0 & 0,9 & 1,1 & 1,1 & 1,1 & 4,5 & 2,8 & 1,9 & 2,8 & 2,4 & 1,7 \\
\hline$J\left(R^{2}=0,75\right)$ & 1,2 & 1,1 & 1,5 & 1,4 & 1,4 & 5,8 & 3,6 & 2,4 & 3,6 & 3,1 & 2,2 \\
\hline$J\left(R^{2}=0,80\right)$ & 1,7 & 1,5 & 1,9 & 1,8 & 1,8 & 7,7 & 4,8 & 3,2 & 4,8 & 4,2 & 2,9 \\
\hline$J\left(R^{2}=0,85\right)$ & 2,3 & 2,1 & 2,8 & 2,6 & 2,6 & 10,9 & 6,7 & 4,5 & 6,9 & 5,9 & 4,1 \\
\hline$J\left(R^{2}=0,90\right)$ & 3,7 & 3,3 & 4,4 & 4,1 & 4,1 & 17,4 & 10,7 & 7,1 & 10,9 & 9,4 & 6,6 \\
\hline$J\left(R^{2}=0,95\right)$ & 7,8 & 7,0 & 9,2 & 8,6 & 8,7 & 36,7 & 22,6 & 15,1 & 23,0 & 19,9 & 13,9 \\
\hline \multicolumn{12}{|c|}{ Massa de vagem, em g } \\
\hline $\mathrm{R}$ & 0,599 & 0,479 & 0,570 & 0,584 & 0,559 & 0,235 & 0,450 & 0,161 & 0,499 & 0,233 & 0,437 \\
\hline $\mathrm{R}^{2}(\%)$ & 85,64 & 78,59 & 84,11 & 84,90 & 83,54 & 55,07 & 76,62 & 43,36 & 79,91 & 54,92 & 75,62 \\
\hline$J\left(R^{2}=0,70\right)$ & 1,6 & 2,5 & 1,8 & 1,7 & 1,8 & 7,6 & 2,8 & 12,2 & 2,3 & 7,7 & 3,0 \\
\hline$J\left(R^{2}=0,75\right)$ & 2,0 & 3,3 & 2,3 & 2,1 & 2,4 & 9,8 & 3,7 & 15,7 & 3,0 & 9,8 & 3,9 \\
\hline$J\left(R^{2}=0,80\right)$ & 2,7 & 4,4 & 3,0 & 2,8 & 3,2 & 13,1 & 4,9 & 20,9 & 4,0 & 13,1 & 5,2 \\
\hline$J\left(R^{2}=0,85\right)$ & 3,8 & 6,2 & 4,3 & 4,0 & 4,5 & 18,5 & 6,9 & 29,6 & 5,7 & 18,6 & 7,3 \\
\hline$J\left(R^{2}=0,90\right)$ & 6,0 & 9,8 & 6,8 & 6,4 & 7,1 & 29,4 & 11,0 & 47,0 & 9,0 & 29,5 & 11,6 \\
\hline$J\left(R^{2}=0,95\right)$ & 12,7 & 20,7 & 14,4 & 13,5 & 15,0 & 62,0 & 23,2 & 99,3 & 19,1 & 62,4 & 24,5 \\
\hline \multicolumn{12}{|c|}{ Massa de grãos por vagem, em g } \\
\hline $\mathrm{R}$ & 0,558 & 0,364 & 0,509 & 0,593 & 0,542 & 0,236 & 0,419 & 0,143 & 0,463 & 0,225 & 0,405 \\
\hline $\mathrm{R}^{2}(\%)$ & 83,45 & 69,57 & 80,56 & 85,35 & 82,54 & 55,25 & 74,26 & 39,93 & 77,49 & 53,74 & 73,14 \\
\hline$J\left(R^{2}=0,70\right)$ & 1,9 & 4,1 & 2,3 & 1,6 & 2,0 & 7,6 & 3,2 & 14,0 & 2,7 & 8,0 & 3,4 \\
\hline$J\left(R^{2}=0,75\right)$ & 2,4 & 5,2 & 2,9 & 2,1 & 2,5 & 9,7 & 4,2 & 18,1 & 3,5 & 10,3 & 4,4 \\
\hline$J\left(R^{2}=0,80\right)$ & 3,2 & 7,0 & 3,9 & 2,7 & 3,4 & 13,0 & 5,5 & 24,1 & 4,6 & 13,8 & 5,9 \\
\hline$J\left(R^{2}=0,85\right)$ & 4,5 & 9,9 & 5,5 & 3,9 & 4,8 & 18,4 & 7,9 & 34,1 & 6,6 & 19,5 & 8,3 \\
\hline$J\left(R^{2}=0,90\right)$ & 7,1 & 15,7 & 8,7 & 6,2 & 7,6 & 29,2 & 12,5 & 54,2 & 10,5 & 31,0 & 13,2 \\
\hline$J\left(R^{2}=0,95\right)$ & 15,1 & 33,2 & 18,3 & 13,0 & 16,1 & 61,5 & 26,3 & 114,3 & 22,1 & 65,4 & 27,9 \\
\hline \multicolumn{12}{|c|}{ Número de grãos por vagem } \\
\hline $\mathrm{R}$ & 0,558 & 0,475 & 0,654 & 0,482 & 0,554 & 0,384 & 0,314 & 0,159 & 0,408 & 0,332 & 0,432 \\
\hline $\mathrm{R}^{2}(\%)$ & 83,44 & 78,33 & 88,31 & 78,85 & 83,22 & 71,37 & 64,66 & 42,98 & 73,42 & 66,53 & 75,25 \\
\hline$J\left(R^{2}=0,70\right)$ & 1,9 & 2,6 & 1,2 & 2,5 & 1,9 & 3,7 & 5,1 & 12,4 & 3,4 & 4,7 & 3,1 \\
\hline$J\left(R^{2}=0,75\right)$ & 2,4 & 3,3 & 1,6 & 3,2 & 2,4 & 4,8 & 6,6 & 15,9 & 4,3 & 6,0 & 3,9 \\
\hline$J\left(R^{2}=0,80\right)$ & 3,2 & 4,4 & 2,1 & 4,3 & 3,2 & 6,4 & 8,7 & 21,2 & 5,8 & 8,0 & 5,3 \\
\hline$J\left(R^{2}=0,85\right)$ & 4,5 & 6,3 & 3,0 & 6,1 & 4,6 & 9,1 & 12,4 & 30,1 & 8,2 & 11,4 & 7,5 \\
\hline$J\left(R^{2}=0,90\right)$ & 7,1 & 10,0 & 4,8 & 9,7 & 7,3 & 14,4 & 19,7 & 47,8 & 13,0 & 18,1 & 11,8 \\
\hline$J\left(R^{2}=0,95\right)$ & 15,1 & 21,0 & 10,1 & 20,4 & 15,3 & 30,5 & 41,5 & 100,8 & 27,5 & 38,2 & 25,0 \\
\hline \multicolumn{12}{|c|}{ Massa de cem grãos, em g } \\
\hline $\mathrm{R}$ & 0,449 & 0,688 & 0,544 & 0,734 & 0,546 & 0,585 & 0,633 & 0,338 & 0,411 & 0,317 & 0,525 \\
\hline $\mathrm{R}^{2}(\%)$ & 76,54 & 89,83 & 82,65 & 91,68 & 82,79 & 84,96 & 87,32 & 67,15 & 73,66 & 65,00 & 81,53 \\
\hline$J\left(R^{2}=0,70\right)$ & 2,9 & 1,1 & 2,0 & 0,8 & 1,9 & 1,7 & 1,4 & 4,6 & 3,3 & 5,0 & 2,1 \\
\hline$J\left(R^{2}=0,75\right)$ & 3,7 & 1,4 & 2,5 & 1,1 & 2,5 & 2,1 & 1,7 & 5,9 & 4,3 & 6,5 & 2,7 \\
\hline$J\left(R^{2}=0,80\right)$ & 4,9 & 1,8 & 3,4 & 1,5 & 3,3 & 2,8 & 2,3 & 7,8 & 5,7 & 8,6 & 3,6 \\
\hline$J\left(R^{2}=0,85\right)$ & 6,9 & 2,6 & 4,8 & 2,1 & 4,7 & 4,0 & 3,3 & 11,1 & 8,1 & 12,2 & 5,1 \\
\hline$J\left(R^{2}=0,90\right)$ & 11,0 & 4,1 & 7,6 & 3,3 & 7,5 & 6,4 & 5,2 & 17,6 & 12,9 & 19,4 & 8,2 \\
\hline$J\left(R^{2}=0,95\right)$ & 23,3 & 8,6 & 16,0 & 6,9 & 15,8 & 13,5 & 11,0 & 37,2 & 27,2 & 40,9 & 17,2 \\
\hline \multicolumn{12}{|c|}{ Produtividade de grãos, em t ha-1 } \\
\hline $\mathrm{R}$ & 0,301 & 0,317 & 0,754 & 0,638 & 0,626 & 0,420 & 0,207 & 0,404 & 0,449 & 0,759 & 0,488 \\
\hline $\mathrm{R}^{2}(\%)$ & 63,28 & 65,04 & 92,45 & 87,60 & 87,02 & 74,35 & 51,05 & 73,03 & 76,56 & 92,64 & 79,19 \\
\hline$J\left(R^{2}=0,70\right)$ & 5,4 & 5,0 & 0,8 & 1,3 & 1,4 & 3,2 & 9,0 & 3,4 & 2,9 & 0,7 & 2,5 \\
\hline$J\left(R^{2}=0,75\right)$ & 7,0 & 6,5 & 1,0 & 1,7 & 1,8 & 4,1 & 11,5 & 4,4 & 3,7 & 1,0 & 3,2 \\
\hline$J\left(R^{2}=0,80\right)$ & 9,3 & 8,6 & 1,3 & 2,3 & 2,4 & 5,5 & 15,3 & 5,9 & 4,9 & 1,3 & 4,2 \\
\hline$J\left(R^{2}=0,85\right)$ & 13,2 & 12,2 & 1,9 & 3,2 & 3,4 & 7,8 & 21,7 & 8,4 & 6,9 & 1,8 & 6,0 \\
\hline$J\left(R^{2}=0,90\right)$ & 20,9 & 19,4 & 2,9 & 5,1 & 5,4 & 12,4 & 34,5 & 13,3 & 11,0 & 2,9 & 9,5 \\
\hline$J\left(R^{2}=0,95\right)$ & 44,1 & 40,9 & 6,2 & 10,8 & 11,3 & 26,2 & 72,9 & 28,1 & 23,3 & 6,0 & 20,0 \\
\hline
\end{tabular}


inteiro de repetiçóes e, consequentemente, a precisão será diferente de $81 \%$.

$\mathrm{O}$ coeficiente de determinação genotípico $\left(\mathrm{R}^{2}\right)$ estimado pela expressão $R^{2}=[J r] /[1+r(J-1)]$, com base na média do coeficiente de repetibilidade (r) entre os dez ensaios e em número fixo de repetições $(\mathrm{J}=4)$, foi de $0,8457,0,7562$, 0,7314, $0,7525,0,8153$ e 0,7919 , respectivamente, para os caracteres comprimento de vagem, massa de vagem, massa de grãos por vagem, número de grãos por vagem, massa de cem grãos e produtividade de grãos (Tabela 3). Então, pode-se inferir que quatro repetições possibilitam detectar diferenças genotípicas com $84,57,75,62,73,14,75,25,81,53,79,19 \%$ de certeza na predição do valor real do genótipo, respectivamente, em relaçấo aos caracteres comprimento de vagem, massa de vagem, massa de grãos por vagem, número de grãos por vagem, massa de cem grãos e produtividade de grãos.

De maneira geral, para os seis caracteres, acréscimos expressivos do coeficiente de determinaçáo genotípico $\left(R^{2}\right)$ foram obtidos com até quatro repetiçóes $(J=4)$. A partir de mais de quatro repetiçóes, houve aumento insignificante do $\mathrm{R}^{2}$, o que reflete em um ganho inexpressivo na predição do valor real do genótipo (Figura 1). Para a produtividade de grãos, caráter com destaque importante nos programas de melhoramento de plantas, constatou-se que ensaios com quatro repetiçóes possibilitam a identificação de genótipos superiores de feijãocaupi em relaçáo à produtividade de grãos com 79,19\% de precisão (próximo à precisão almejada de $81 \%$ ). Essa precisão de 79,19\% é semelhante às obtidas em outras culturas, ou seja, pesquisas revelaram que, para avaliação da produtividade de grãos, ensaios com quatro repetiçōes possibilitaram a identificação de genótipos superiores de feijāo (Cargnelutti et al., 2009), de soja (Storck et al., 2009), de milho (Cargnelutti et al., 2010) e de arroz irrigado (Cargnelutti et al., 2012), com 85, 80, 81 e $79 \%$ de precisão, respectivamente. Portanto, pode-se inferir que metas de acurácia seletiva de $90 \%$ têm sido alcançadas em ensaios de feijão, soja, milho, arroz irrigado e feijão-caupi, com número de repetiçóes relativamente menor que as seis recomendadas teoricamente por Resende \& Duarte (2007). No entanto, o uso de maior número maior de repetiçóes deve ser encorajado para maximizar a precisão experimental.
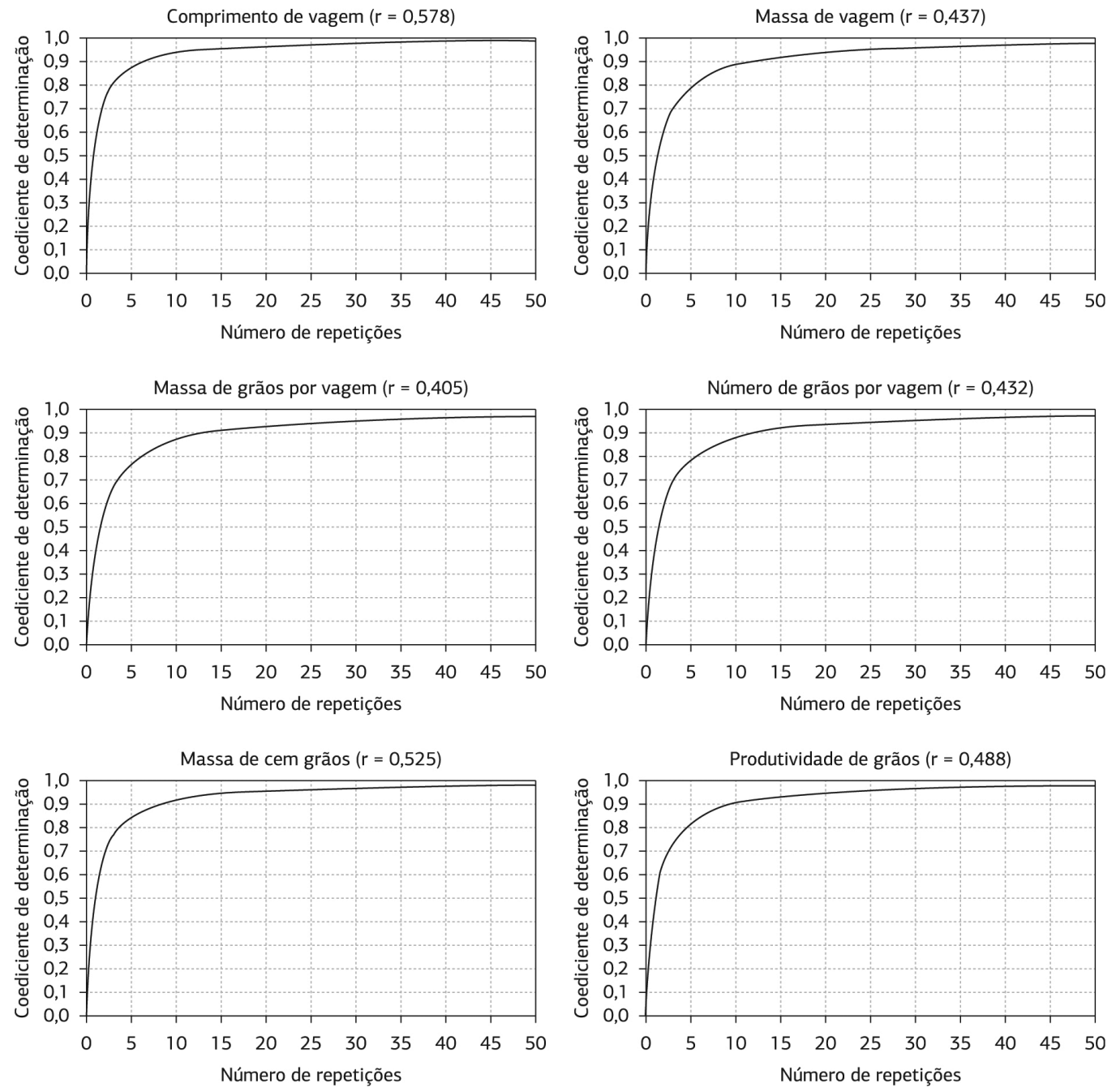

Figura 1. Coeficientes de determinação genotípico $\left(\mathrm{R}^{2}\right)$ em função do número de mediçôes (repetiçôes) (J), com base no coeficiente de repetibilidade (r) médio de dez ensaios de avaliação de caracteres de genótipos de feijão-caupi. 


\section{CONCLUSÃO}

Ensaios com quatro repetições identificam genótipos superiores de feijão-caupi em relação aos caracteres comprimento de vagem, massa de vagem, massa de grãos por vagem, número de grãos por vagem, massa de cem grãos e produtividade de grãos com, respectivamente, $84,57,75,62$, $73,14,75,25,81,53$ e 79,19\% de exatidão no prognóstico de seu valor real.

\section{AGRADECIMENTOS}

Ao Conselho Nacional de Desenvolvimento Científico e Tecnológico (CNPq), pela concessáo de bolsa de Produtividade em Pesquisa ao autor Alberto Cargnelutti Filho.

\section{REFERÊNCIAS}

Almeida, W. S., Fernandes, F. R. B., Teófilo, E. M., \& Bertini, C. H. C. M. (2014). Correlation and path analysis in components of grain yield of cowpea genotypes. Revista Ciência Agronômica, 45, 726-736. http://dx.doi.org/10.1590/S1806-66902014000400010.

Andrade, F. N., Rocha, M. M., Gomes, R. L. F., Freire, F. R., Fo., \& Ramos, S. R. R. (2010). Estimativas de parâmetros genéticos em genótipos de feijão-caupi avaliados para feijão fresco. Revista Ciência Agronômica, 41, 253-258. http://dx.doi.org/10.1590/ S1806-66902010000200012.

Barros, M. A., Rocha, M. M., Gomes, R. L. F., Silva, K. J. D., \& Neves, A. C. (2013). Adaptabilidade e estabilidade produtiva de feijãocaupi de porte semiprostrado. Pesquisa Agropecuaria Brasileira, 48, 403-410. http://dx.doi.org/10.1590/S0100-204X2013000400008.

Cargnelutti, A., Fo., \& Gonçalves, E. C. P. (2011). Estimativa do número de repetições para a avaliação de caracteres de produtividade e de morfologia em genótipos de soja. Comunicata Scientiae, 2, 25 33. Recuperado em 24 de novembro de 2015, de http://comunicata. ufpi.br/index.php/comunicata/article/view/81/53

Cargnelutti, A., Fo., \& Guadagnin, J. P. (2011). Planejamento experimental em milho. Revista Ciência Agronômica, 42, 1009-1016. http://dx.doi.org/10.1590/S1806-66902011000400025.

Cargnelutti, A., Fo., Marchesan, E., Silva, L. S., \& Toebe, M. (2012). Medidas de precisão experimental e número de repetiçôes em ensaios de genótipos de arroz irrigado. Pesquisa Agropecuaria Brasileira, 47, 336-343. http://dx.doi.org/10.1590/S0100-204X2012000300004.

Cargnelutti, A., Fo., \& Ribeiro, N. D. (2010). Número de repetiçóes para avaliação de caracteres de produção, fenologia e morfologia de cultivares de feijāo. Ciência Rural, 40, 2446-2453. http://dx.doi. org/10.1590/S0103-84782010001200002.

Cargnelutti, A., Fo., Ribeiro, N. D., \& Storck, L. (2009). Número de repetiçóes para a comparação de cultivares de feijão. Ciência Rural, 39, 2419-2424. http://dx.doi.org/10.1590/S0103-84782009000900006.

Cargnelutti, A., Fo., Storck, L., \& Guadagnin, J. P. (2010). Número de repetiçôes para a comparação de cultivares de milho. Ciência Rural, 40, 1023-1030. http://dx.doi.org/10.1590/S0103-84782010005000073.
Correa, A. M., Ceccon, G., Correa, C. M. A., \& Delben, D. S. (2012). Estimativas de parâmetros genéticos e correlaçóes entre caracteres fenológicos e morfoagronômicos em feijão-caupi. Revista Ceres, 59, 88-94. http://dx.doi.org/10.1590/S0034-737X2012000100013.

Cruz, C. D. (2006). Programa Genes: biometria. Viçosa: UFV. 382 p.

Cruz, C. D. (2013). GENES - a software package for analysis in experimental statistics and quantitative genetics. Acta Scientiarum Agronomy, 35, 271-276. http://dx.doi.org/10.4025/actasciagron. v35i3.21251.

Cruz, C. D., \& Regazzi, A. J. (1997). Modelos biométricos aplicados ao melhoramento genético (2 ed.). Viçosa: UFV. 390 p.

Matos, C. H. A., Fo., Gomes, R. L. F., Rocha, M. M., Freire, F. R., Fo., \& Lopes, A. C. A. (2009). Potencial produtivo de progênies de feijão-caupi com arquitetura ereta de planta. Ciência Rural, 39, 348-354. http://dx.doi.org/10.1590/S0103-84782009000200006.

Monico, J. F. G., Póz, A. P. D., Galo, M., Santos, M. C., \& Oliveira, L. C. (2009). Acurácia e precisão: revendo os conceitos de forma acurada. Boletim de Ciências Geodésicas, 15, 469-483. Recuperado em 04 de novembro de 2014, de http://ojs.c3sl.ufpr.br/ojs/index. php/bcg/article/view/15513/10363

Oliveira, O. M. S., Silva, J. F., Ferreira, F. M., Klehm, C. S., \& Borges, C. V. (2013). Associaçóes genotípicas entre componentes de produção e caracteres agronômicos em feijão-caupi. Revista Ciência Agronômica, 44, 851-857. http://dx.doi.org/10.1590/S1806-66902013000400023.

Resende, M. D. V., \& Duarte, J. B. (2007). Precisão e controle de qualidade em experimentos de avaliaçáo de cultivares. Pesquisa Agropecuária Tropical, 37, 182-194. Recuperado em 25 de outubro de 2014, de http://www.revistas.ufg.br/index.php/pat/article/ viewFile/1867/1773

Santos, A., Ceccon, G., Davide, L. M. C., Correa, A. M., \& Alves, V. B. (2014a). Correlations and path analysis of yield components in cowpea. Crop Breeding and Applied Biotechnology, 14, 82-87. http://dx.doi.org/10.1590/1984-70332014v14n2a15.

Santos, J. A. S., Teodoro, P. E., Correa, A. M., Soares, C. M. G., Ribeiro, L. P., \& Abreu, H. K. A. (2014b). Desempenho agronômico e divergência genética entre genótipos de feijão-caupi cultivados no ecótono Cerrado/Pantanal. Bragantia, 73, 377-382. http://dx.doi. org/10.1590/1678-4499.0250.

Santos, J. A. S., Soares, C. M. G., Corrêa, A. M., Teodoro, P. E., Ribeiro, L. P., \& Abreu, H. K. A. (2014c). Agronomic performance and genetic dissimilarity among cowpea (Vigna unguiculata (L.) Walp.) genotypes. Global Advanced Research Journal of Agricultural Science, 3, 271-277. Recuperado em 25 de outubro de 2014, de http://garj. org/garjas/pdf/2014/August/Santos\%20et\%20al.pdf

Silva, J. A., \& Neves, J. A. (2011). Componentes de produção e suas correlaçôes em genótipos de feijão-caupi em cultivo de sequeiro e irrigado. Revista Ciência Agronômica, 42, 702-713. http://dx.doi. org/10.1590/S1806-66902011000300017.

Storck, L., Cargnelutti, A., Fo., Lúcio, A. D., \& Lopes, S. J. (2009). Método de Papadakis e número de repetiçôes em experimentos de soja. Ciência Rural, 39, 977-982. http://dx.doi.org/10.1590/S010384782009005000027.

Storck, L., Garcia, D. C., Lopes, S. J., \& Estefanel, V. (2011). Experimentação vegetal (3 ed.). Santa Maria: UFSM. 200 p. 